\title{
Influence of Laser Power on Improving the Wear Properties of Laser-Deposited Ti-6Al-4V+B $\mathrm{B}_{4} \mathrm{C}$ Composite
}

\author{
Mutiu F. Erinosho* - Esther T. Akinlabi \\ University of Johannesburg, Department of Mechanical Engineering Science, South Africa
}

\begin{abstract}
Titanium and its alloys have possessed outstanding properties such as high specific strength, good oxidation and corrosion resistance; which have made them extensively suitable for use in the aeronautical, medical, automobile, marine and chemical industries. This paper presents the impact of laser power on the microstructure and the wear properties of titanium matrix Ti-6Al-4V+B $\mathrm{C}$ composites. The laser power was varied from $0.8 \mathrm{~kW}$ to $2.2 \mathrm{~kW}$ while keeping other contributing parameters constant. The microstructural effects were characterized by increasing $\alpha$-Ti lamella and coarse Widmanstettan structures as the laser power was increased, with the inclusion of 20 wt $\%$ of $B_{4} C$. The mechanical action during wear test has created a loop shape with inner and outer radii on the surface of the laser-deposited composites. The wear thickness, depth and COF were taken into account; with the sample $C$ deposited at a laser power of $1.8 \mathrm{~kW}$ and scanning speed of $1 \mathrm{~m} / \mathrm{min}$ having the lowest wear loss of $0.119 \mathrm{~mm}^{3}$. The substrate exhibited the shallowest wear depth, and the reason is attributed to the compressive nature of the material. The interlace of $\mathrm{B}_{4} \mathrm{C}$ in the titanium matrix has improved the properties of the laser-formed composites. Keywords: laser metal deposition, microstructure, wear measurement, Ti- $6 \mathrm{Al}-4 \mathrm{~V}+\mathrm{B}_{4} \mathrm{C}$ composite
\end{abstract}

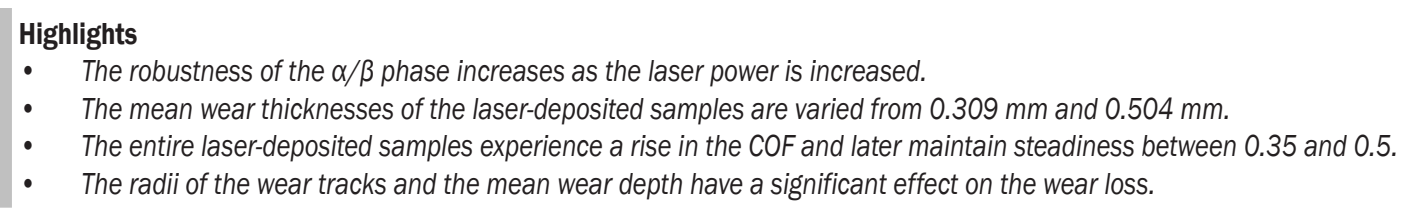

\section{INTRODUCTION}

Laser metal deposition (LMD) is one of the most effective means of manufacturing complex geometrical components with high efficiency [1]. This process involves the manufacturing of a complex component directly from a three- dimensional (3D) computer-aided design (CAD) system [2], and it is characterized by an energy balance that is affected by the part being fabricated, the geometrical features of the substrate and the ambient temperature of the process [3]. This energy is however transformed into heat energy that creates the melt pool on the substrate [4]. Titanium and its alloys are metals that have been widely used in industries due to their desirable properties, including good corrosion resistance, high-strength-to-weight ratio, and retention of properties at high temperatures [2]. Despite all the fascinating properties of the alloy, they still possess poor wear resistance; however, the improvement in their properties has given room for other alloys to be integrated. $\mathrm{TiB}$ and $\mathrm{TiC}$ are widely preferred reinforcement agents for titanium due to their strength, interfacial bonding, excellent thermodynamic stability and related thermal expansion coefficient with the titanium matrix [5]. A small cylindrical bar of (Ti$6 \mathrm{Al}-4 \mathrm{~V}+\mathrm{B}$ ) with a dimension of $9 \mathrm{~mm}$ by $6 \mathrm{~mm}$ was made to undergo a compressive test and compared with the parent material, the Ti-6Al-4V alloy. After deformation, it was reported that a $50 \%$ reduction in height was achieved and the microstructure of (Ti$6 \mathrm{Al}-4 \mathrm{~V}+\mathrm{B}$ ) sample was characterized with strainfree $\alpha$-colonies and more homogenous dislocation density distribution as compared with the parent material [6]. Another research was conducted on cast (Ti-6Al-4V $+x \mathrm{~B}$ ) samples; where $x$ is $0.05 \mathrm{wt} \%, 0.10$ wt $\%$ and 0.40 wt $\%$ respectively. It was discovered that the microstructural refinement of the cast samples led to an increase in the yield and the ultimate tensile strength of the casted alloys. The strain to failure ratio was also reported to increase with a small addition of boron. However, revealed further that an increase in boron content would lead to an increase in fracture toughness [7], and a general improvement in the cracking resistance [8] to [10]. Premixed titanium and boron were blended in weight ratio 8:1 with sodium silicate solution and laser-deposited onto Ti-6Al-4V alloy substrate. Hard ceramic compounds of $\mathrm{TiB}$ and $\mathrm{TiB}_{2}$ were revealed to be formed in the deposited alloy. Similarly, high microhardness values and excellent wear resistance of the laser deposited samples were also realized. However, the results were reported to have considerably enhanced the load-bearing capability of the substrate [11]. $\mathrm{TiO}_{2}$ was sintered with $\mathrm{B}_{4} \mathrm{C}$ powder in steel dies at $80 \mathrm{MPa}$ for 1 hour after preheating to $1500{ }^{\circ} \mathrm{C}$ for 2 hours in a vacuum 
furnace. It was discovered that the resulting hardness values of the compacted composites ranged from 800 $\mathrm{HV}$ to $2500 \mathrm{HV}$ [12]. $\mathrm{B}_{4} \mathrm{C}$ is an extremely hard boroncarbon ceramic used for ballistic armour, tank armour, bulletproof vests etc. The friction and wear behaviour of micro-textured cemented carbide was investigated against titanium alloy grade 5 using the dry sliding means. The texture filled with lubricant was reported to effectively improve the friction and wear of the cemented carbide disk against the titanium alloy balls [13]. The effect of carbon and boron was studied in Ti-48Al alloys. The crystal structure of $\mathrm{B}_{4} \mathrm{C}$ formed was found to lessen the accumulations of boron atoms. In one study, Ti-48Al- $0.2 \mathrm{~B}_{4} \mathrm{C}$ was reported to have excellent mechanical properties amongst other alloys. In addition, the microstructure with uniformly distributed borides and carbides was reported to be a good fracture toughness enhancer for the Ti-48Al$0.2 \mathrm{~B}_{4} \mathrm{C}$ alloys [14]. A broad approach to refurbish titanium turbine blades by direct laser deposition was investigated. The coatings involved the use of titanium carbide with boron carbide and tungsten carbide particles for an air foil shroud platform. $5 \mathrm{wt}$ $\%$ of boron carbide and 5 wt $\%$ of tungsten carbide were added to $\mathrm{TiC}$ powder. Titanium boride obtained in the coating contains uniformly distributed large solid heat-resistant boron carbide and tungsten carbide particles. The hardness of $520 \mathrm{HV}_{0.1}$ was achieved in the coating matrix [15].

Series of works have been carried out with different ceramics especially boron carbide [15] to [18], but there some paucities in the laser cladding of Ti-6Al-4V with $\mathrm{B}_{4} \mathrm{C}$ composite remain. Nevertheless, this paper presents the influence of laser power on improving the laser-deposited Ti-6Al-4V $+\mathrm{B}_{4} \mathrm{C}$ composites through the microstructure and the wear properties for nuclear applications. The cladding requires a weight percentage ratio of $4: 1$ of Ti-6Al-4V alloy and $\mathrm{B}_{4} \mathrm{C}$. Here laser powers have been varied between $0.8 \mathrm{~kW}$ and $2.2 \mathrm{~kW}$ while the scanning speed of $1 \mathrm{~m} / \mathrm{min}$, powder flow rate of $3.2 \mathrm{rpm}$ for Ti-6Al$4 \mathrm{~V}$ alloy, $0.8 \mathrm{rpm}$ for $\mathrm{B}_{4} \mathrm{C}$ and gas flow rate of 2.0 are kept constant.

\section{EXPERIMENTAL TECHNIQUE}

The primary technique used in this experiment is grouped under laser cladding. The experiment was conducted at the National Laser Centre, Council for Scientific and Industrial Research (NLC-CSIR) on a $3.0 \mathrm{~kW}$ Ytterbium Laser System. Both the laser system and a Kuka robot are interconnected for the operation. The substrate used is a grit-blasted, $99.6 \%$ Ti-6Al-4V alloy plate with dimensions of $(72 \times 72 \times 5) \mathrm{mm}^{3}$. The experimental matrixes used are highlighted in Table 1, and the samples are labelled from A to E.

Table 1. Experimental matrix

\begin{tabular}{lccccc}
\hline Sample name & A & B & C & D & E \\
\hline Laser power $[\mathrm{kW}]$ & 0.8 & 1.6 & 1.8 & 2.0 & 2.2 \\
\hline Scanning speed $[\mathrm{m} / \mathrm{min}]$ & $=1$, Gas flow rate $[\mathrm{l} / \mathrm{min}]=2$ \\
Powder flow rate $[\mathrm{rpm}]:$ Ti-6Al-4V $=3.2 ; \mathrm{B}_{4} \mathrm{C}=0.8$ & \\
\hline
\end{tabular}

The particle size of the Ti-6Al-4V alloy powder used for the deposition ranges between $150 \mu \mathrm{m}$ to 200 $\mu \mathrm{m}$ while the particle size of the $\mathrm{B}_{4} \mathrm{C}$ powder is about $45 \mu \mathrm{m}$ to $90 \mu \mathrm{m}$. Ten tracks with $50 \%$ overlap were made on the substrate. During the deposition process, the clad is shielded with argon gas in order to prevent environmental oxidation. In this research work, 20 wt $\%$ of $\mathrm{B}_{4} \mathrm{C}$ powder was deposited with Ti-6Al-4V alloy powder via the laser deposition process and deposited in a single- layer-multiple-track approach to characterize the wear properties.

\subsection{Microstructure}

According to E3-11 ASTM standard [19], all the samples are sectioned laterally, mounted, ground and polished. The Kroll's reagent was prepared for the etchant with $\mathrm{H}_{2} \mathrm{O}, \mathrm{HF}$, and $\mathrm{HNO}_{3}$ in the ratio 48:1:3 following the guidelines in the Struers application note for metallurgical preparation of titanium [20]. Each sample was etched for 30 seconds before optical microscopic and SEM observations using BX51M Olympus microscope and TESCAN machine. The SEM uses a VEGA TC software and is equipped with an X-MAX instrument.

\subsection{Wear}

A CETR, UTM-2 tribometer, operating with linear reciprocating motion drive located at the Metallurgy and Chemical Laboratory of the Tshwane University of Technology in Pretoria West Campus, South Africa was used to test for wear. Rotary wear was conducted on the deposited surface of the entire sample for 1000 $\mathrm{s}$ using a constant force of $25 \mathrm{~N}$ and speed of 60 $\mathrm{rpm}$. Prior to commencing the test, the samples were mounted tightly onto a metal plate which was placed in a reciprocating base and adjusted accordingly to ensure that the tungsten carbide ball is well located on the deposited surface. The tribometer measured the wear depth (WD) as well as the coefficient of friction (COF). 


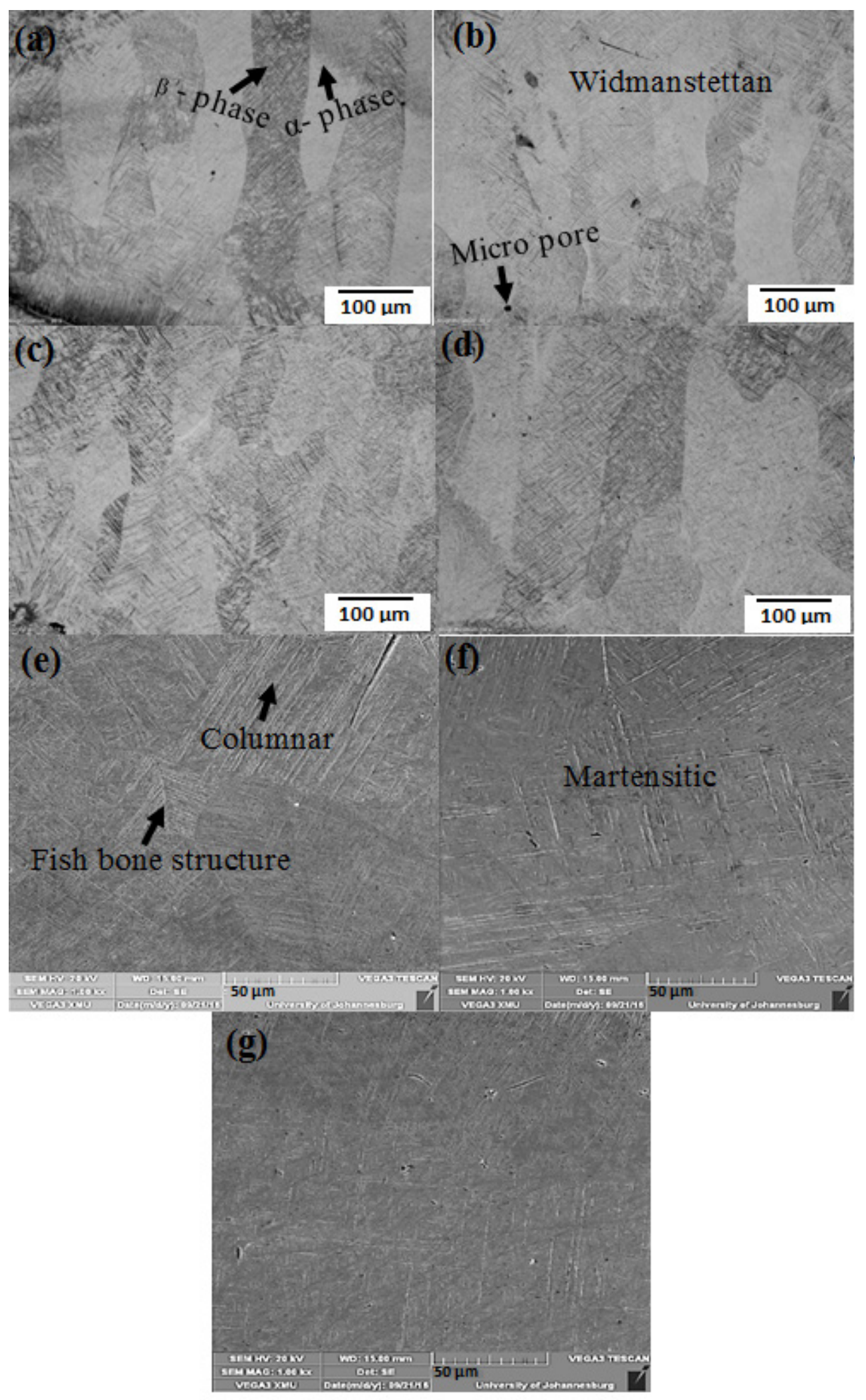

Fig. 1. Microstructures of laser deposited Ti- $6 \mathrm{Al}-4 \mathrm{~V}+B 4 C$ composite: a) sample $A: 0.8 \mathrm{~kW}$; b) sample $B: 1.6 \mathrm{~kW}$; c) sample C: $1.8 \mathrm{~kW}$; d) sample D: $2 \mathrm{~kW}$; e) SEM of sample B: $1.6 \mathrm{~kW}$ with columnar grains; f) SEM of sample D: $2 \mathrm{~kW}$ with martensitic phases; and g) SEM of sample E: $2.2 \mathrm{~kW}$ 
Using Eqs. (1) to (4), derived by Klenam and Chown [21], the wear loss was calculated as follows:

$$
\begin{gathered}
R_{2}=\sqrt{\frac{A_{2}}{\pi}}, \\
R_{1}=R_{2}-t, \\
V_{s}=\pi \times\left(R_{2}^{2}-R_{1}^{2}\right) \times d_{\text {max }}, \\
s=2 \pi \times R_{\text {mean }}=\pi \times\left(2 R_{2}-t\right),
\end{gathered}
$$

where $V_{s}$ is wear volume $\left[\mathrm{mm}^{3}\right], R_{2}$ outer radius [mm], $R_{1}$ inner radius [mm], $t$ mean track thickness $[\mathrm{mm}] . d_{\max }$ maximum wear depth [mm], and $s$ sliding distance $[\mathrm{mm}]$.

\section{RESULTS AND DISCUSSION}

The microstructural behaviour and the rotary wear properties of the laser- deposited Ti- $6 \mathrm{Al}-4 \mathrm{~V}+\mathrm{B}_{4} \mathrm{C}$ composites are presented in detail in this section.

\subsection{Microstructural Examination}

The deposits, the fusion zones, and the heat-affected zones (HAZ) of the laser-deposited samples are taken into consideration for the microstructures. Figs. 1a to $\mathrm{d}$ show the microstructures of samples A, B, C, and D deposited at the laser powers of $0.8 \mathrm{~kW}, 1.6 \mathrm{~kW}, 1.8$ $\mathrm{kW}$, and $2.0 \mathrm{~kW}$, respectively.

The microstructures of the laser deposited composites show the formation of $\alpha$-Ti phase and $\beta$-Ti phase, and these were elongated towards the fusion zone and terminated at the zone. Globular microstructures were established just immediately after the fusion zone and grow epitaxially within this region and later disappear towards the HAZ(s). The robustness of the $\alpha / \beta$ phases increases as the laser power was increased. At high laser power, the coarseness of the microstructure is more obvious than the composite deposited with the previous laser powers due to the energy density of the laser beam. The intensity of the laser beam at high laser power creates more heat input as well as a wider melt pool to accommodate the volume of metal deposit. Widmanstettan structures are also observed in all the microstructures and look harsh and rigid with the agglomeration of $20 \mathrm{wt} \%$ of $\mathrm{B}_{4} \mathrm{C}$ added. The microstructures of the Ti-6Al-4V alloy after boriding show more lamellar, which typically enhance the formation of $(\alpha+\beta)$-Ti alloys [16]. The thickness of the $\alpha$-Ti lamella formed is a significant feature since it influences the mechanical properties of the Ti6Al-4V alloy [17]. Under the SEM, a fish bone-like of $\alpha$-Ti martensitic phase was observed in sample B deposited with a laser power of $1.6 \mathrm{~kW}$ and scanning speed of $1 \mathrm{~m} / \mathrm{min}$; and this can be attributed to the stability accrued by $\mathrm{B}_{4} \mathrm{C}$ within the deposited region. Columnar grains growing perpendicularly to the heat sink direction were also observed in the deposit. There is an equiaxed transition of these grains, and these were as a result of the steep temperature gradient and the cooling rate effect during the solidification process.

\subsection{Wear Properties}

The wear scars of the substrate and the laser-deposited Ti-6Al- $4 \mathrm{~V}+\mathrm{B}_{4} \mathrm{C}$ composite are shown in Fig. 2. A form of ring-type wear was inscribed on the surface of the samples.

The ring has an inner and outer radius which are measured from the centre and labelled as $R_{1}$ and $R_{2}$ respectively. The surface topographies of the wear scars of the laser-deposited Ti- $6 \mathrm{Al}-4 \mathrm{~V}+\mathrm{B}_{4} \mathrm{C}$
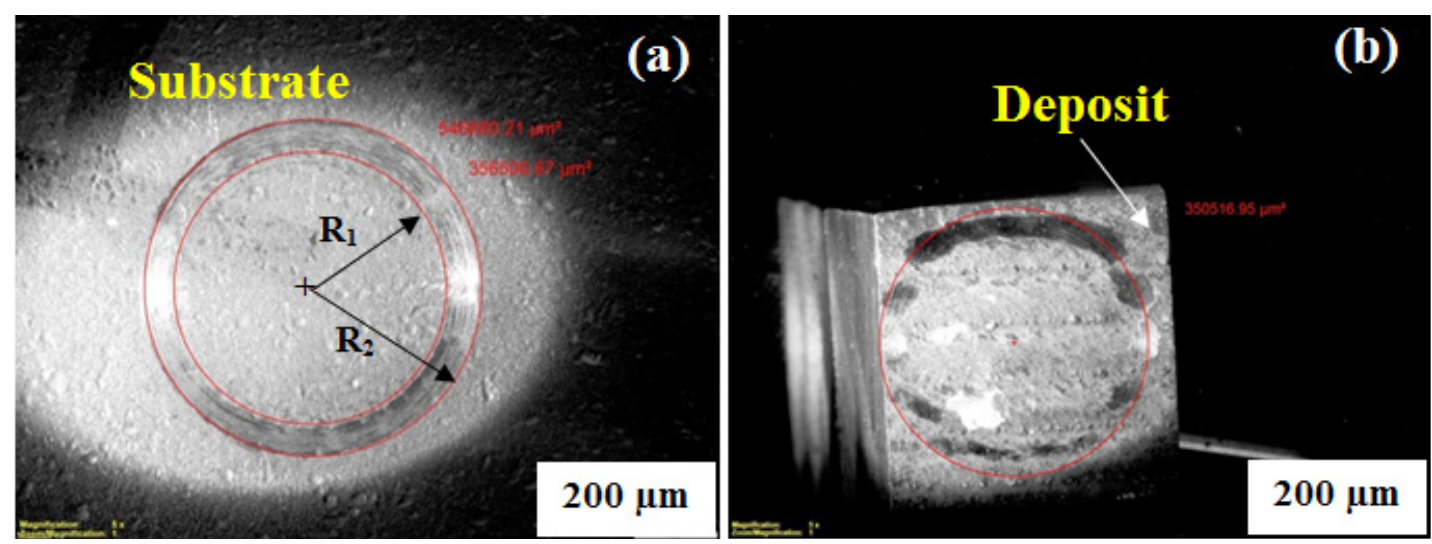

Fig. 2. Wear track of the substrate and the Ti-6Al-4V+B4C deposit at $2.0 \mathrm{~kW}$ 

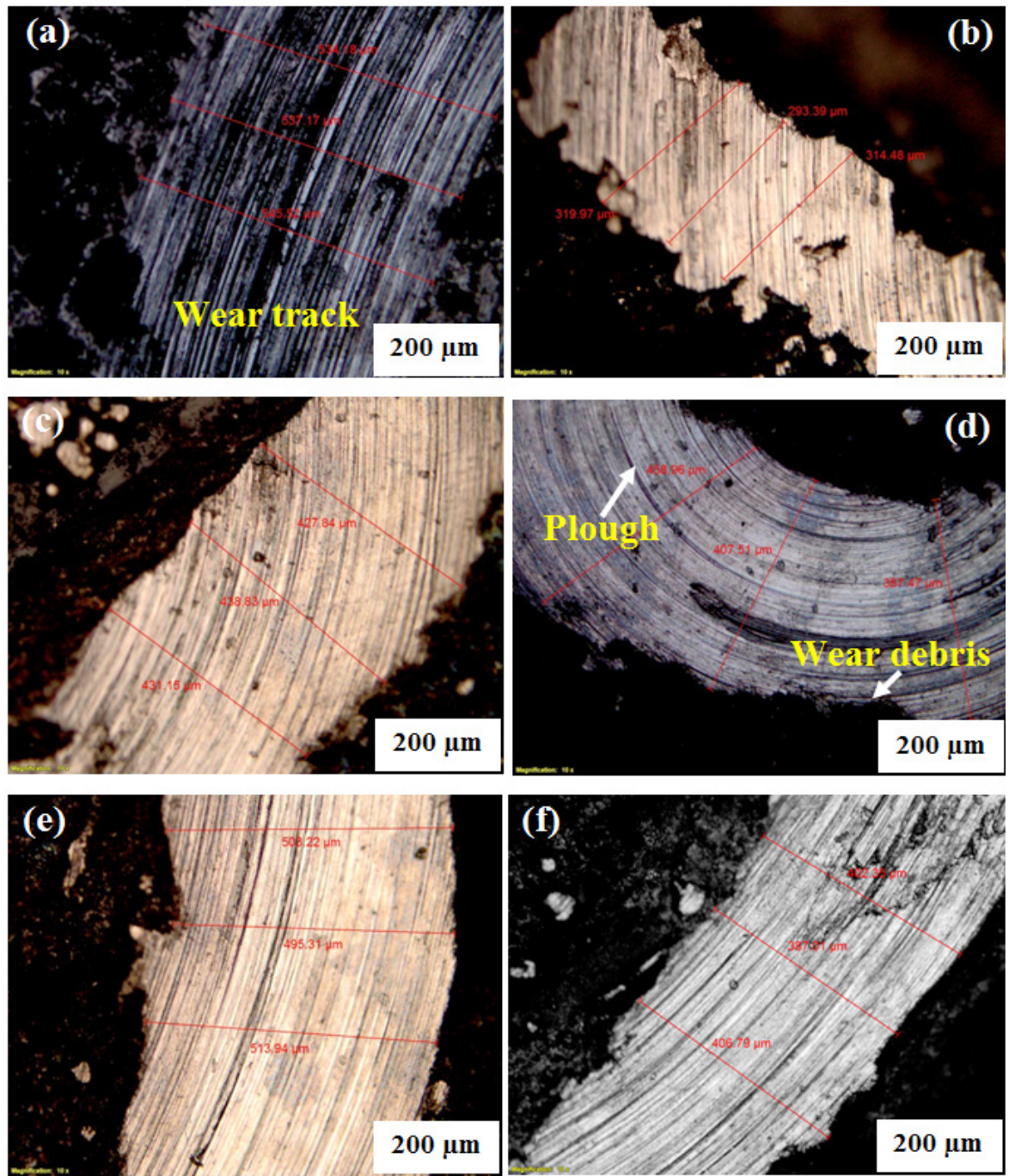

Fig. 3. Wear track of the laser deposited samples showing the thicknesses: a) substrate, b) sample A deposited at laser power of $0.8 \mathrm{~kW}$; c) sample $B$ deposited at laser power of $1.6 \mathrm{~kW}$; d) sample C deposited at laser power of $1.8 \mathrm{~kW}$; e) sample $D$ deposited at laser power of $2 \mathrm{~kW}$; f) sample $E$ deposited at laser power of $2.2 \mathrm{~kW}$

composites after the dry rotary wear tests are shown in Fig. 3.

The sliding friction that exists between the tip of the tungsten carbide ball and the surface of the laser-deposited composites was instigated by the action force. The wear morphology was inscribed as a result of the mechanical action which created a ringshaped indentation on the surface of the composites. The thicknesses of the wear scars were measured and the average is taken into consideration. This is an essential parameter for the wear volume and wear rate in order to predict the life expectancy of the composite when subjected to wear. Rubbing exists between the tungsten carbide ball and the surface of the laserdeposited composites in a circular manner; and due to the vertically applied force, wear was initiated on the surfaces as a result of the friction. Thin grooves were generated on the scar in the rubbing direction. The substrate shows a wider thickness as compared to other wear topographies.

Fig. 4 depicts the mean wear thicknesses of the substrate and the laser-deposited Ti- $6 \mathrm{Al}-4 \mathrm{~V}+\mathrm{B}_{4} \mathrm{C}$ composites from samples A to E.

Fig. 5 shows the profiling of the wear depth of the substrate and the laser-deposited Ti- $6 \mathrm{Al}-4 \mathrm{~V}+\mathrm{B}_{4} \mathrm{C}$ composites.

At different points, three thicknesses of the wear scar per sample were measured with the optical microscope, and the mean was established. The mean wear thicknesses of the laser-deposited samples varied 


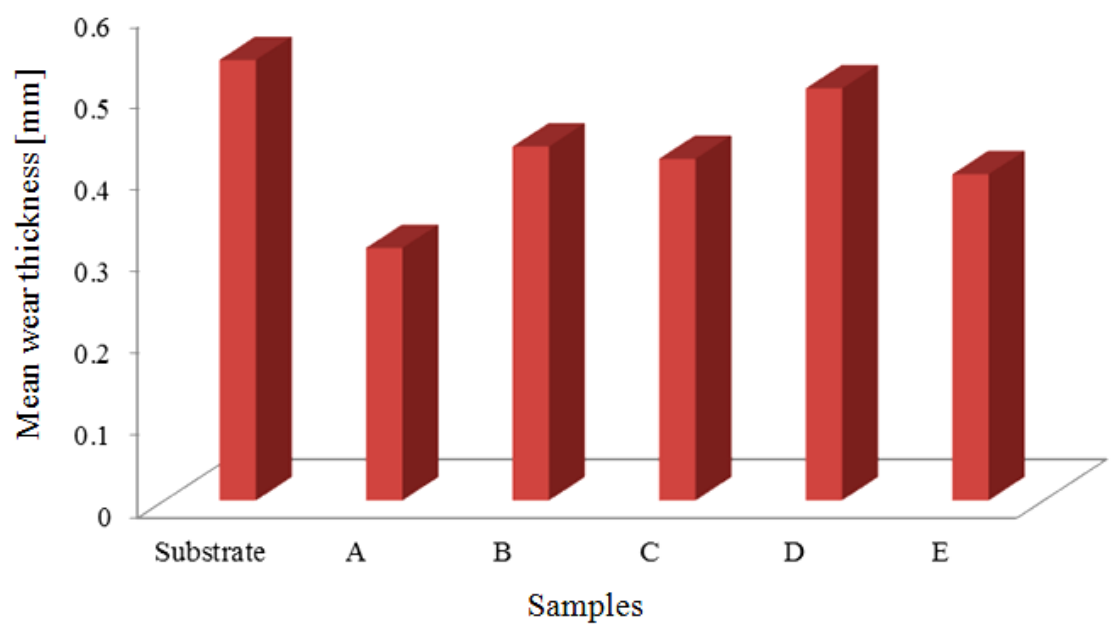

Fig. 4. Plot of mean wear thickness

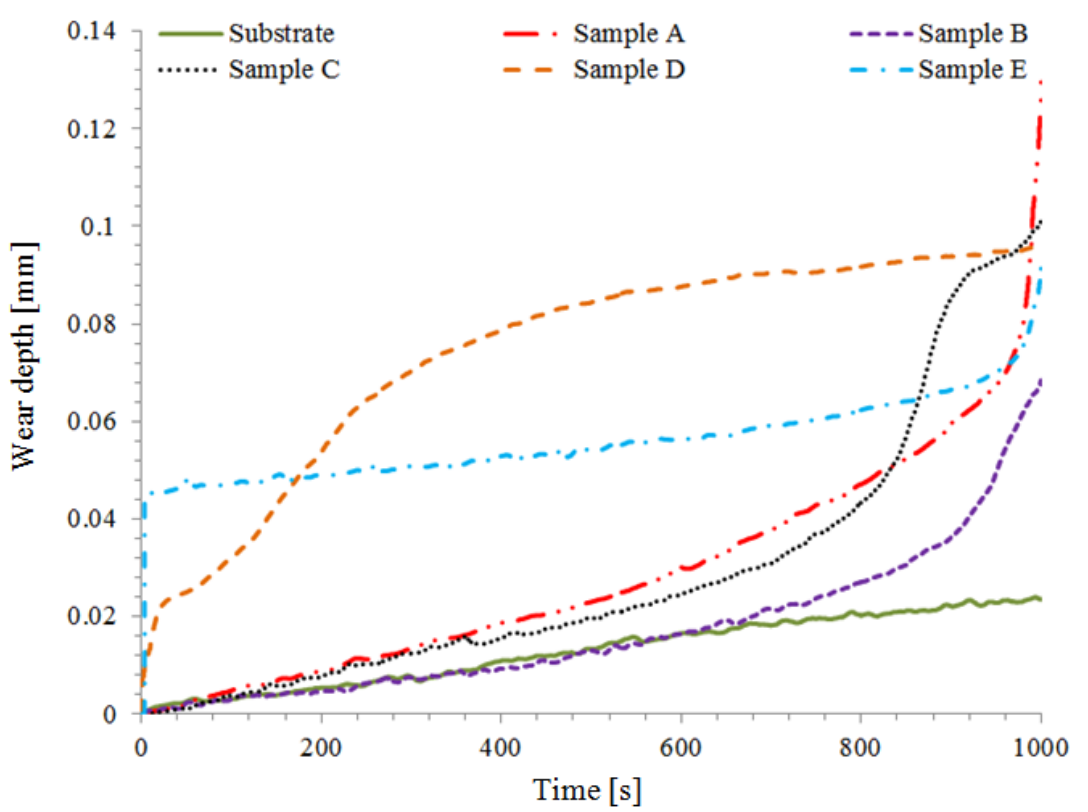

Fig. 5. Profiling of wear depth versus time

from $0.309 \mathrm{~mm}$ and $0.504 \mathrm{~mm}$. Sample A deposited at a laser power of $0.8 \mathrm{~kW}$ and scanning speed of 1 $\mathrm{m} / \mathrm{min}$ depicts the lowest wear thickness of 0.309 $\mathrm{mm}$ whilst the substrate exhibits the highest mean wear thickness of $0.539 \mathrm{~mm}$. This sample depicts the lowest wear thickness among all other deposited samples; which could be as a result of partly and inhomogeneous melting of $\mathrm{B}_{4} \mathrm{C}$ in the alloy with the low laser power used. From the scattered plot of the wear depth against the time, it can be deduced that there is a linear rise in the trend from the start time to the end time at 1000 seconds. The substrate shows the lowest average wear depth of $0.013 \mathrm{~mm}$, while among other composites, sample D deposited at a laser power of $1.8 \mathrm{~kW}$ and scanning speed of $1 \mathrm{~m} / \mathrm{min}$ exhibits the highest average wear depth of $0.074 \mathrm{~mm}$. The rolled nature and the compactness of the substrate have a greater effect on its wear depth. Sample E deposited at a laser power of $2.2 \mathrm{~kW}$ exhibits a constant wear depth at zero (0) time till $0.045 \mathrm{~mm}$ and later maintains a slow steady rise till the end.

Table 2 illustrates the wear loss $\left(V_{s}\right)$ of the substrate as well as all the participating laser-deposited samples from samples A to E, respectively.

The wear loss was initiated as a result of the frictional force and the abrasive wear between the 
Table 2. Wear loss $\left(V_{s}\right)$ of the substrate and the laser-deposited specimen

\begin{tabular}{lcccccc}
\hline Sample name & Substrate & Sample A & Sample B & Sample C & Sample D & Sample E \\
\hline Wear loss, $V_{S}\left[\mathrm{~mm}^{3}\right]$ & 0.712 & 0.329 & 0.179 & 0.119 & 0.515 & 0.399 \\
\hline
\end{tabular}

tungsten ball and the top surface of the laser-deposited composite. The round thicker ridge created at the engraved path-way shows the degree of the wear loss. The $V_{s}$ measured between the laser-deposited samples A to $\mathrm{E}$ is from $0.119 \mathrm{~mm}^{3}$ to $0.399 \mathrm{~mm}^{3}$. Among the deposited Ti-6Al-4V+B ${ }_{4} \mathrm{C}$ specimens, sample $\mathrm{C}$ deposited with a laser power of $1.8 \mathrm{~kW}$ exhibits the lowest $V_{s}$ of $0.119 \mathrm{~mm}^{3}$ while the as received substrate has the $V_{s}$ of $0.712 \mathrm{~mm}^{3}$ which is higher than all the deposited samples. The $V_{s}$ has been improved with the addition of $\mathrm{B}_{4} \mathrm{C}$ based on the results obtained as shown in Table 2. The radii of the wear tracks and the mean wear depth have a significant effect on the wear loss. The variations between the melting points of the two participating powders as well as their densities have also contributed to the improvement in wear properties. From the values obtained, it can be deduced that, as the laser power was increased from $0.8 \mathrm{~kW}$ to $1.8 \mathrm{~kW}$, the wear loss was found to decrease, and later showed a sudden increase from $0.119 \mathrm{~mm}^{3}$ in sample C to $0.515 \mathrm{~mm}^{3}$ in sample $\mathrm{D}$ at a laser power of $2 \mathrm{~kW}$. For sample E, the $V_{s}$ was dropped to $0.399 \mathrm{~mm}^{3}$. This behaviour can be attributed to the melting that took place at high laser power as well as the slow cooling rate.
The COF of the as-received substrate as well as the laser-deposited $\mathrm{Ti}-6 \mathrm{Al}-4 \mathrm{~V}+\mathrm{B}_{4} \mathrm{C}$ composites were also analysed and presented in Fig 6.

The COF of all the participating samples is varied between 0.382 and 0.424 . Sample A deposited at a laser power of $0.8 \mathrm{~kW}$ and scanning speed of $1 \mathrm{~m} /$ min exhibits the lowest COF of 0.382 while sample $\mathrm{B}$ deposited at a laser power of $1.6 \mathrm{~kW}$ shows the highest COF of 0.424 , although the value is close to that of the substrate with a COF of 0.419 . However, these do not serve as the yardstick for enhancing their wear loss. The COF of all the samples reaches a maximum before they oscillate between limits and maintain steadiness in the range of 0.25 and 0.5 . All the samples experience a rise in the COF from the starting point at zero seconds and maintain steadiness in the COF between 0.35 and approximately 0.5 .

\section{CONCLUSION}

The coagulation of titanium alloy with boron carbide through the laser deposition process was successfully achieved, and the properties were considerably enhanced. The characteristics conducted on the microstructure of the titanium alloy matrix Ti-6Al$4 \mathrm{~V}+\mathrm{B}_{4} \mathrm{C}$ composite revealed some globular structures growing epitaxially towards the heat-affected zone. It

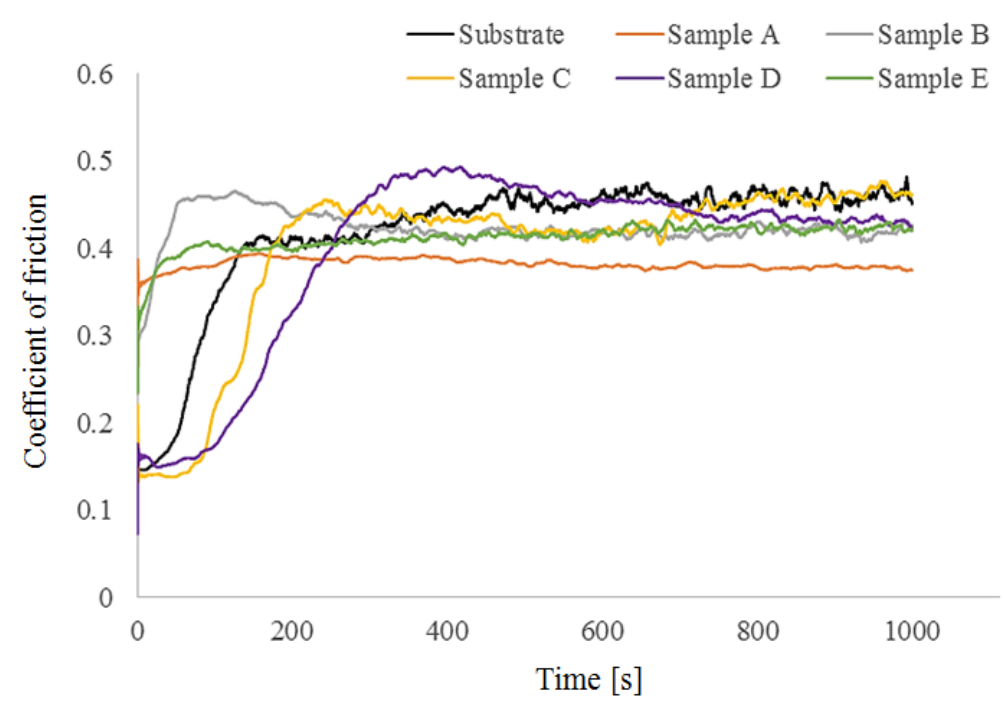

Fig. 6. COF of the substrate and the laser-deposited Ti- $6 \mathrm{Al}-4 \mathrm{~V}+\mathrm{B} 4 \mathrm{C}$ composites 
was also evident that the robustness of the $\alpha / \beta$ phases is as a result of the increase in the laser power. The rubbing that exists between the hard tungsten carbide ball and the surface of the laser-deposited composites facilitated a circular wear scar with different thicknesses and wear depths. Sample A deposited at a laser power of $0.8 \mathrm{~kW}$ and scanning speed of $1 \mathrm{~m} /$ min depicted the lowest wear thickness and COF of $0.309 \mathrm{~mm}$ and 0.382 but does not assure a reduced wear loss due to the wear depth and surface defect. The wear loss has been improved with the addition of 20 wt $\%$ of $\mathrm{B}_{4} \mathrm{C}$. The metal matrix Ti- $6 \mathrm{Al}-4 \mathrm{~V}+\mathrm{B}_{4} \mathrm{C}$ composites can be applied in the aerospace industries for the repair of parts due to the improved properties.

\section{REFERENCES}

[1] Erinosho, M.F., Akinlabi, E.T, Pityana, S. (2015). Influence of processing parameters on laser metal deposited copper and titanium alloy composites. Transactions of Nonferrous Metals Society of China, vol. 25, no. 8, p. 2608-2616, Dol:10.1016/ S1003-6326(15)63882-1.

[2] Mahamood, R.M., Akinlabi, E.T. (2015). Effect of laser power and powder flow rate on the wear resistance behaviour of laser metal deposited TiC / Ti6Al4V composites. Materials Today: Proceedings, vol. 2, no. 4-5, p. 2679-2686, D0l:10.1016/j. matpr.2015.07.233.

[3] Tiang, L., Ruan, J., Sparks, T.E., Landers, R.G., Liou F. (2009). Layer-to-layer height control of Laser Metal Deposition processes. American Control Conference, p. 5582-5587, D0l:10.1109/ACC.2009.5160407.

[4] Farayibi, P.K. (2014). Laser Cladding of Ti-6Al-4V with Carbide and Boride Reinforcements using Wire and Powder Feedstock, $\mathrm{PhD}$ thesis University of Nottingham, Nottingham.

[5] Balaji, V.S., Kumaran, S. (2014). Densification and microstructural studies of titanium-boron carbide (B4C) powder mixture during spark plasma sintering. Powder Technology, vol. 264, p. 536-540, D0l:10.1016/j. powtec.2014.05.050.

[6] Roy, S., Sarkar, A., Suwas, S. (2010). On characterization of deformation microstructure in Boron modified $\mathrm{Ti}-6 \mathrm{Al}-4 \mathrm{~V}$ alloy. Materials Science and Engineering: A, vol. 528, no. 1, p. 449-458, D0I:10.1016/j.msea.2010.09.026.

[7] Sen, I., Tamirisakandala, S., Miracle, D.B, Ramamurty, U. (2007). Microstructural effects on the mechanical behavior of B-modified Ti-6Al-4V alloys. Acta Materialia, vol. 55, no. 15, p. 4983-4993, D0I:10.1016/j.actamat.2007.05.009.

[8] Skorokhod, VI.V., Krstic, V.D. (2000). Processing, microstructure, and mechanical properties of B4CTiB2 particulate sintered composites I. Pressureless sintering and microstructure evolution. Powder Metallurgy and Metal Ceramics, vol. 39, no. 7-8, p. 414-423, DOI:10.1023/A:1026625909365.

[9] Gutmanas, E.Y, Gotman, I. (2000). Reactive synthesis of ceramic matrix composites under pressure. Ceramics
International, vol. 26, no. 7, p. 699-703, D0l:10.1016/S02728842(00)00007-9.

[10] Itoh, H., Tsunekawa, Y., Tago, S., Iwahara, H. (1993). Synthesis and sinterability of composite powder of the TiB2-B4C system. Journal of Alloys and Compounds, vol. 191, no. 2, p. 193-195, DOl:10.1016/0925-8388(93)90063-S.

[11] Tian, Y.S., Zhang, Q.Y., Wang, D.Y. (2009). Study on the microstructures and properties of the boride layers laser fabricated on Ti-6Al-4V alloy. Journal of Materials Processing Technology, vol. 209, no. 6, p. 2887-2891, Dol:10.1016/j. jmatprotec.2008.06.043.

[12] Levin, L., Frage, N., Dariel, M.P. (2000). A novel approach for the preparation of B4C-based cermets. International Journal of Refractory Metals and Hard Materials, vol. 18, no. 2-3, p. 131-135, DOI:10.1016/S0263-4368(00)00012-3.

[13] Lian, Y., Mu, C., Wang, L., Yao, B., Deng, J., Lei, S. (2018). Numerical simulation and experimental investigation on friction and wear behaviour of micro-textured cemented carbide in dry sliding against TC4 titanium alloy balls, International Journal of Refractory Metals \& Hard Materials, vol. 73, p. 121-131, D0I:10.1016/j.jijrmhm.2018.02.006.

[14] Li, M., Xiao, S., Xiao, L., Xu, L., Tian, J., Chen, Y. (2017). Effects of carbon and boron addition on microstructure and mechanical properties of TiAl alloys. Journal of Alloys and Compounds, vol. 728, p. 206-221, Dol:10.1016/j. jallcom.2017.08.211.

[15] Gorunov, A.I. (2018). Complex refurbishment of titanium turbine blades by applying heat-resistant coatings by direct metal deposition. Engineering Failure Analysis, vol. 86, p. 115130, D0I:10.1016/j.engfailanal.2018.01.001.

[16] Qin, L., Liu, C., Yang, K., Tang, B. (2013). Characteristics and wear performance of borided Ti6Al4V alloy prepared by double glow plasma surface alloying. Surface and Coatings Technology, vol. 225, p. 92-96, Dol:10.1016/j. surfcoat.2013.02.053.

[17] Jackson, M., Jones, N.G., Dye, D., Dashwood, R.J. (2009). Effect of initial microstructure on plastic flow behaviour during isothermal forging of Ti-10V-2Fe-3Al. Material Science and Engineering: A, vol. 501, no. 1-2, p. 248-254, Dol:10.1016/j. msea.2008.09.071.

[18] Makuch, N., Kulka, M., Dziarski, P., Przestacki, D. (2014). Laser surface alloying of commercially pure titanium with boron and carbon. Optics and Lasers in Engineering, vol. 57, no. 64-81, D0I:10.1016/j.optlaseng.2014.01.019.

[19] ASTM E3-11 (2017). Standard Guide for Preparation of Metallographic Specimens, ASTM International, West Conshohocken, D0I:10.1520/E0003-11R17.

[20] Struers Application Note on Titanium (2013). From http:// www.struers.com/resources/elements/12/104827/ Application_Note_Titanium _English.pdf, accessed on 25-082013.

[21] Klenam, D.E.P., Chown, L.H., Papo, M.J., Cornish, L.A. (2015). Characterization of railway stock axle produced from mediumcarbon steel. DST-AMI Nuclear Materials Development Network Conference, p. 125-137, Dol:10.13140/RG.2.1.1383.1128. 